This is a post-peer-review, pre-copyedit version of an article published in European Journal of Pediatrics. The final authenticated version is available online at: https://link.springer.com/article/10.1007/s00431-0183304-x.

\title{
Epidemiology of gastrostomy insertion for children and adolescents with intellectual disability.
}

Kingsley Wong ${ }^{1}$ Kingsley.Wong @ telethonkids.org.au; Helen Leonard ${ }^{1}$ Helen.Leonard@telethonkids.org.au; Glenn Pearson ${ }^{1}$ Glenn.Pearson@telethonkids.org.au; Emma J Glasson ${ }^{1}$ Emma.Glasson@telethonkids.org.au; David Forbes ${ }^{2,3}$ David.Forbes@ health.wa.gov.au; Madhur Ravikumara ${ }^{4}$ Madhur.Ravikumara@health.wa.gov.au; Peter Jacoby ${ }^{1}$

Peter.Jacoby@telethonkids.org.au; Jenny Bourke ${ }^{1}$ Jenny.Bourke@ telethonkids.org.au;

Preeyaporn Srasuebkul ${ }^{5}$ preeyaporn.srasuebkul@ unsw.edu.au; Julian Trollor ${ }^{5}$ J.Trollor@unsw.edu.au; Andrew Wilson" ${ }^{1,6,7,9}$ Andrew.Wilson@ @ealth.wa.gov.au; Lakshmi Nagarajan $^{8}$ Lakshmi.Nagarajan@ @ealth.wa.gov.au; Jenny Downs ${ }^{1,9}$ Jenny.Downs@telethonkids.org.au.

Affiliations: ${ }^{1}$ Telethon Kids Institute, Centre for Child Health Research, The University of Western Australia, Perth, Australia; ${ }^{2}$ Medical School, The University of Western Australia, Perth, Australia; ${ }^{3}$ Department of Health, Government of Western Australia, Perth, Australia; ${ }^{4}$ Department of Gastroenterology, Perth Children's Hospital, Perth, Australia; ${ }^{5}$ Department of Developmental Disability Neuropsychiatry, School of Psychiatry, UNSW Sydney, Sydney, Australia; ${ }^{6}$ Department of Respiratory Medicine, Perth Children's Hospital, Perth, Australia; ${ }^{7}$ School of Paediatrics, The University of Western Australia, Perth, Australia; ${ }^{8}$ Children's Neuroscience Service, Department of Neurology, Perth Children's Hospital, Perth, Australia; ${ }^{9}$ School of Physiotherapy and Exercise Science, Curtin University, Perth, Australia.

Corresponding author: Jenny Downs, $\mathrm{PhD}$, Telethon Kids Institute, The University of Western Australia, PO Box 855, West Perth, Western Australia 6872, Australia. Email: Jenny.Downs@telethonkids.org.au,Phone: +61411161138

Acknowledgements: This project was funded by an Australian National Health \& Medical Research Council project grant (APP1103746). HL is supported by an Australian National Health \& Medical Research Council Senior Research Fellowship (APP1117105). We gratefully acknowledge staff at the WA Data Linkage Branch, Department of Health and the data custodians, including the Western Australian Register of Developmental Anomalies, for their assistance in obtaining the linked data used in this project and manuscript review. We acknowledge the Department of Communities (previously the Disability Services Commission), the WA Department of Education, the Catholic Education Office, and the Association of Independent Schools of WA for assistance with data collection for the IDEA database. 


\section{Contributors' Statement Page}

Dr Wong conceptualized and designed the study, was responsible for obtaining funding, performed the linked data analysis, participated in the initial writing of the manuscript, and reviewed and revised the manuscript.

A/Prof Leonard conceptualised and designed the study, was responsible for obtaining funding, coded the indications for gastrostomy according to hospitalization data, and reviewed and revised the manuscript.

Mr Pearson provided interpretation for the analysis of Aboriginality data, and critically reviewed and revised the manuscript with reference to Aboriginality.

Dr Glasson drafted the initial manuscript, and reviewed and revised the manuscript from conceptualization to completion.

Prof Forbes conceptualized and designed the study, was responsible for obtaining funding, reviewed and revised the manuscript, and critically reviewed the manuscript for important intellectual content regarding aspects of gastroenterology.

Dr Ravikumara conceptualized and designed the study, was responsible for obtaining funding, reviewed and revised the manuscript, and critically reviewed the manuscript for important intellectual content regarding aspects of gastroenterology.

A/Prof Jacoby conceptualized and designed the study, was responsible for obtaining funding, provided specialist statistical support, and reviewed and revised the manuscript.

Ms Bourke collected data for the study, and critically reviewed the manuscript for important intellectual content regarding aspects of intellectual disability.

Dr Srasuebkul reviewed and critically reviewed the manuscript for important intellectual content regarding aspects of intellectual disability.

Prof Trollor conceptualized and designed the study, was responsible for obtaining funding, reviewed and revised the manuscript, and critically reviewed the manuscript for important intellectual content regarding aspects of intellectual disability.

Dr Wilson conceptualized and designed the study, was responsible for obtaining funding, reviewed and revised the manuscript, and critically reviewed the manuscript for important intellectual content regarding aspects of pediatric medicine.

Prof Nagarajan conceptualized and designed the study, was responsible for obtaining funding, reviewed and revised the manuscript, and critically reviewed the manuscript for important intellectual content regarding aspects of pediatric medicine.

A/Prof Jenny Downs conceptualized and designed the study, was responsible for obtaining funding coordinated and supervised linked data collection, reviewed and revised the manuscript and was the principal investigator of the research.

All authors approved the final manuscript as submitted and agree to be accountable for all aspects of the work.

Word count: 2800

Number of Tables: 3

Number of Figures: 4 


\begin{abstract}
The largest group of recipients of pediatric gastrostomy have neurological impairment with intellectual disability (ID). This study investigated trends in first gastrostomy insertion according to markers of disadvantage and ID etiology. Linked administrative and health data collected over a 32-year study period (1983-2014) for children with ID born between 1983-2009 in Western Australia were examined. The annual incidence rate change over calendar year was calculated for all children and according to socioeconomic status, geographical remoteness and Aboriginality. The most likely causes of ID were identified using available diagnosis codes in the linked dataset. Of 11,729 children with ID, $325(2.8 \%)$ received a first gastrostomy within the study period. The incidence rate was highest in the 0-2 age group and there was an increasing incidence trend with calendar time for each age group under 6 years of age. This rate change was greatest in children from the lowest socioeconomic status quintile, who lived in regional/remote areas or who were Aboriginal. The two largest identified groups of ID were genetically caused syndromes $(15.1 \%)$ and neonatal encephalopathy (14.8\%). Conclusion: Gastrostomy is increasingly used in multiple neurological conditions associated with ID, with no apparent accessibility barriers in terms of socioeconomic status, remoteness or Aboriginality.
\end{abstract}

Keywords: Gastrostomy, intellectual disability, epidemiology, accessibility, incidence.

Abbreviations: ACHI (Australian Classification of Health Intervention), APC (Annual Percentage Change), CI (Confidence Interval), HMDC (Hospital Morbidity Data Collection), ICD (International Classification of Disease), ICPM (International Classification of Procedures in Medicine), ID (Intellectual Disability), IDEA (Intellectual Disability Exploring Answers), IRSAD (Index of Relative Socio-Economic Advantage and Disadvantage), MNS (Midwives Notification System), PEG (Percutaneous Endoscopic Gastrostomy), WA (Western Australia), WARDA (Western Australian Register for Developmental Anomalies).

\title{
What is Known:
}

- The use of gastrostomy insertion in pediatrics is increasing and the most common recipients during childhood have neurological impairment, most of whom also have intellectual disability (ID).

\section{What is New:}

- Nearly three percent of children with ID had gastrostomy insertion performed, with the highest incidence in children under three years of age.

- The two largest identified groups of ID were genetically caused syndromes and neonatal encephalopathy.

- Gastrostomy use across different social groups was equitable in the Australian setting. 


\section{INTRODUCTION}

Around 1.5-2.0\% of children born each year develop an intellectual disability (ID)[1]. Compared to unaffected children, these children have more physical disability and medical comorbidities (e.g. epilepsy[2]), are up to ten times more likely to be hospitalised[3] and have a nine-fold increase in mortality[4]. Children with complex medical needs often have feeding difficulties. Consequences include poor nutrition and growth, aspiration of food and fluids into the lungs, recurrent chest infections and progressive lung disease.[5] Families and carers often find feeding routines time-consuming[6,7], compounding other high-level care demands. Gastrostomy is one management option to improve daily feeding regimens, long-term nutrition and medication administration[8]. It is used across a range of indications[9-13] but children with neurological impairments have more frequent use[6,11,12,14] including a substantial proportion who have $\mathrm{ID}[15]$.

The United Nations Convention on the Rights of Persons with Disabilities clarifies that quality heath care should be provided without discrimination on the basis of disability[16]. Principles guiding equitable health care delivery include consideration of availability, accessibility, acceptability, adaptability and quality, known as the 4AQ framework[17]. Children with ID are more likely to live in families of low socioeconomic status and rural residence, and have higher representation among Indigenous groups[18-23]. These factors could make them especially vulnerable to health inequalities. Given the high frequency of feeding difficulties in ID, it is important to understand the barriers and enablers that affect accessibility to this procedure.

Understanding the diagnostic characteristics of children with ID who receive gastrostomy will provide a platform from which to evaluate patient care and outcomes. Accordingly, this study aimed to describe the incidence of gastrostomy insertion within a population of children and adolescents with ID in Western Australia (WA) over a 32-year period using linked data, investigate factors influencing gastrostomy use and identify etiological groupings of ID for individuals receiving gastrostomy. 


\section{MATERIALS AND METHODS}

We conducted a retrospective birth cohort study using linked health administrative, disability and population databases available in the state of WA (2014 population: 2.5 million[24]). The study observation period was from 1 January 1983 to 31 December 2014.

\section{Study population and data sources}

The WA population is centralized, approximately $80 \%$ living in the greater area of its capital city Perth[25] and all pediatric gastrostomy insertions are performed at the only tertiary children's hospital. We included linked population-based health, disability and administrative data sets[26-28] in our analyses.

The state Midwives Notification System (MNS)[28] was used to identify all children born alive in WA between 1 January 1983 and 31 December 2009. To account for the lag between birth and identification of ID and to ensure that most of the eligible children were diagnosed, children were required to be at least 5 years of age at the time of data extraction. Thus, cases were defined as children diagnosed between 1 January 1983 and 31 December 2014 based on identification of ID from either one of the following data sources: 1) the Intellectual Disability Exploring Answers (IDEA) database[29] which collects information on children with ID from statewide disability service registration and/or school education records; or 2) the WA Register of Developmental Anomalies (WARDA)[28] which incorporates data on cases with both birth defects and cerebral palsy. Most cases were identified from IDEA $(n=11,525,98.2 \%)$ and WARDA contributed an additional $204(1.8 \%)$ cases. For all identified cases of ID, demographic, disability and health data were extracted from the IDEA database, WARDA, MNS, the Hospital Morbidity Data Collection (HMDC), and death registrations[28,29].

Socioeconomic status was measured using the Index of Relative Socio-Economic Advantage and Disadvantage (IRSAD) centile $(<=20 \%, 21-40 \%, 41-60 \%, 61-80 \%,>80 \%)$ and remoteness of 
residence was based on the Accessibility and Remoteness Index for Australia score (major cities, regional or remote). Both indicators were based on birth home address at the Census Collection District level $(1996,2001,2006)$ or the Statistical Area 1 level calculated by the Australian Bureau of Statistics[30]. Aboriginality was defined as being a person of Aboriginal descent, and was coded as either Aboriginal or non-Aboriginal using a validated algorithm[31].

The primary outcome measure was defined as first hospitalization in children younger than 18 years for gastrostomy insertion, including open gastrostomy and percutaneous endoscopic gastrostomy (PEG) placements, within the study period. For hospitalizations up to December 1987, the International Classification of Procedures in Medicine (ICPM) codes were used to identify hospitalizations during which gastrostomy insertion was performed [Open: 5-431, 5-432; PEG: N/A]. Thereafter, the International Classification of Disease, ninth revision (ICD-9-CM) (Jan 1988 - Jun 1999) and the Australian Classification of Health Intervention (ACHI) (Jul 1999 - Dec 2014) codes were used [ICD-9-CM - Open 43.19; PEG 43.11, and ACHI - Open 30375-07, 90302-00; PEG 30481-00, 30482-00]. Fundoplication, a procedure that may be performed in conjunction with gastrostomy insertion, was also identified (ICPM - 5-445; ICD-9-CM - 44.66; ACHI - 30527-0(0-5) 30529-00, 30529-01, 30530-00).

\section{Covariates}

Age at admission for first gastrostomy insertion was categorized into six groups: 0-2 years, 3-5 years, 6-8 years, 9-11 years, 12-14 years and 15-17 years. Birth year was grouped by 5-year period intervals after 1984: 1983-1984, 1985-1989, 1990-1994, 1995-1999, 2000-2004, and 2005-2009.

\section{Categorization of etiologies of ID in children with gastrostomy} ICD-9-CM and ICD-10-AM codes for all recorded hospitalizations were reviewed for individuals who had a gastrostomy insertion to identify the most likely reason (causal or associated factors) and then grouped accordingly[32]. 
Statistical Analysis

Prevalence of gastrostomy insertion in children with ID by birth year group was calculated by dividing the number of children in the specific birth year interval who received a gastrostomy insertion before 18 years of age by the number of live births within the birth period and was reported as cases per 100 live births.

We examined how the occurrence of gastrostomy insertion changed by calendar year by investigating the annual incidence rate over time. The rate was calculated based on the number of first gastrostomy insertions performed in individuals aged younger than 18 years in each calendar year divided by the person-time at risk of receiving the procedure from the start of the relevant year until date of first gastrostomy insertion, date of death or end of the year, whichever occurred first. The incidence rate was measured in cases per 10,000 person-years. Overall age-specific rates over calendar year, as well as the rates by socioeconomic status, remoteness area and Aboriginality, were presented. Our analysis focused on periods with full data coverage for each age group given that birth cohort study methodology had a staggered start. For example, for the age group 3-5 years, the trend commenced in 1988 because data were available for children aged 3, 4 and 5 years in that year. We estimated the linear annual percentage change (APC) of incidence rate for each age group from Poisson regression models with the number of incident cases within that age group during each year as the dependent variable and the total corresponding time at risk as the offset. Robust standard errors were used to allow for overdispersion. In the subgroup analyses, difference in agespecific APCs between the two levels of each variable (Aboriginality: Aboriginal v. nonAboriginal; socioeconomic status: most disadvantaged ( $1^{\text {st }}$ IRSAD quintile) v. more advantaged $\left(2^{\text {nd }}-5^{\text {th }}\right.$ IRSAD quintile); remoteness area: regional/remote $v$. major cities) were estimated using an interaction term of calendar year and the subgroup variable. Adjusted effects were obtained by rerunning the model using all three variables and their interaction terms. 
The median and interquartile range of age of first gastrostomy insertion for each diagnostic

105

group were described. The association between diagnostic group and sex was examined using Pearson's chi-squared test of independence.

\section{Ethical approvals}

Ethical approval was obtained from the Department of Health WA (\#2016/32) and the Western Australian Aboriginal Health Ethics Committee (747).

\section{RESULTS}

We identified 11,729 individuals with ID. Of these, 325 children (2.8\%) underwent gastrostomy insertion between 1983 and 2014. Characteristics of the study population by gastrostomy insertion status are shown in Table 1. The prevalence increased from 1.9 per 100 live births $(95 \%$ confidence interval [CI] 1.5,2.5) among those born in 1983-1989 to 3.4 per 100 live births (95\% CI 2.8,4.0) in the 2000-2009 birth cohort. More than half (53.5\%) were male, approximately four-fifths (86.1\%) non-Aboriginal, and nearly two-thirds (61.5\%) lived in major cities. Gastrostomy was usually performed early in life (0-5 years: 69.8\%) and the median age at admission was 3 years 4 months (interquartile range 1.6-7.9 years). New gastrostomy insertion was predominantly performed using the percutaneous endoscopic technique (84.6\%), with $28.0 \%(n=91)$ also having a fundoplication. Majority of the fundoplication surgery was carried out at time of first gastrostomy insertion (50.5\%, $\mathrm{n}=46)$, and the rest were performed either after $(40.7 \%, \mathrm{n}=37)$ or before $(8.8 \%, \mathrm{n}=8)$ gastrostomy.

\section{Incidence rate of gastrostomy insertion in intellectual disability}

The age-specific incidence rates of first gastrostomy insertion from 1983 to 2014 for individuals with ID are presented in Figure 1. Since 1983, rates increased among children younger than three years (APC 6.9\%, 95\% CI 4.4,9.4). A similar trend was observed for children aged 3-5 years (APC $4.6 \%, 95 \%$ CI 1.1,8.2) and 6-8 years (APC 3.9\%, 95\% CI -2.7,11.0). The trend was flat among 
preadolescent children (9-11 years APC -0.1\%, 95\% CI -6.9,7.1; $12-14$ years APC - $1.1 \%, 95 \%$ CI $11.5,10.5)$ and the incidence of new cases decreased in the oldest age group (15-17 years) (APC $8.2 \%, 95 \%$ CI $-17.6,2.4)$.

\section{Subgroup analyses}

Age-specific incidence rates of first gastrostomy insertion by socioeconomic status, remoteness area and Aboriginality subgroups are presented in Figures 2, 3 and 4, respectively. Adjusted for Aboriginality and remoteness area at birth, there was a small increase in rate of change comparing children of families from the most disadvantaged group ( $1^{\text {st }}$ IRSAD quintile) to those in more advantaged group ( $2^{\text {nd }}-5^{\text {th }}$ IRSAD quintiles) in the $0-2$ years (adjusted APC difference $1.8 \%, 95 \%$ CI -3.8,7.7) and 3-5 years (adjusted APC difference 2.6\%, 95\% CI -4.7,10.5) age groups (Table 2). Similar increase was observed in the same age groups comparing individuals of families from regional/remote areas to those from major cities (0-2 years: adjusted APC difference 3.4, 95\% CI 2.1,9.2; 3-5 years: adjusted APC difference 3.0, 95\% CI -4.3,10.9). More pronounced difference was observed among Aboriginal children compared to their non-Aboriginal peers when the procedure was performed at 0-2 years (adjusted APC difference 12.6\%, 95\% CI 4.4,21.4) and 3-5 years (adjusted APC difference 13.6\%, 95\% CI 0.8,28.0).

\section{Causes for ID among children with gastrostomy}

The majority $(n=10,644,90.7 \%)$ had mild or moderate ID (Table 1$)$. In those who underwent gastrostomy insertion the majority had severe ID $(60.0 \%, 22.1 \%$ of all children with severe ID) and only just over a third had mild/moderate ID $(36.3 \%, 1.1 \%$ of all children with mild/moderate ID) (Table 1). The most likely cause for ID in those who underwent gastrostomy insertion is shown in Table 3. The largest subgroup $(n=110,33.8 \%)$ were those classified with a presumed genetic cause. Among the specific causes, neonatal encephalopathy $(n=48,14.8 \%)$ accounted for a considerable proportion whilst congenital infections $(n=21,6.5 \%)$ and post-natal causes (injury, asphyxia, 
meningitis or encephalitis) were less common $(n=23,7.1 \%)$. The youngest median age of gastrostomy insertion was observed for children with a chromosomal disorder (1.7 years, IQR 1.03.3 years) whereas children with injury or asphyxia underwent gastrostomy insertion later (8.1 years, IQR 3.7-14.2 years). Chromosomal abnormalities, multiple congenital abnormalities and epileptic encephalopathy were more common in males who underwent gastrostomy, and prematurity, genetic syndromes, hydrocephalus and congenital infection were more common in females $(\mathrm{p}<0.001$, Table 3$)$.

\section{DISCUSSION}

We used linked data to investigate gastrostomy use in children with ID in WA over a 32-year period where the prevalence was 277 cases per 10,000 live births $(2.8 \%)$, compared with 6.7 cases per 10,000 live births in the general pediatric population[15]. The increasing prevalence of gastrostomy use may be influenced by its perceived value in reducing carer burden[6,33], enabling home- rather than hospital-based care[34,35], clinician preferences[36] and the importance of stabilizing nutritional support over the longer term. Increasing use may also reflect more proactive clinical management during the early years, in parallel with a remarkable period of social and political change that supports greater use of community- or home-based care for children with a disability[37-39] and enhanced accessibility and choice for individuals with disabilities[16,38,40]. Parents and carers have a greater role in seeking solutions with clinicians to ameliorate daily challenges in their children's lives, including consideration of gastrostomy insertion to stabilize feeding difficulties.

We examined both socioeconomic and geographic factors that could influence accessibility to gastrostomy, as well as the influence of Aboriginality. The prevalence of ID is greater among the proportion of the population with the highest level of disadvantage $[19,20,41]$ and we observed a small increase in gastrostomy use among the lowest socioeconomic quintile in children younger than six years, after adjusting for the effects of remoteness area and Aboriginality. This finding is 
contrary to the usual patterns for other conditions, procedures or health services where accessibility is often limited in groups associated with low socioeconomic status[42,43].

Overall, we found a slightly higher incidence of gastrostomy insertion among young children whose mothers lived outside the major cities at the time of their birth. Western Australia has a vast land mass (2.3 million square kilometers) and for those in rural Australia, residential isolation can impact access to health care services[44]. However, geographic distance from the tertiary care center in Perth did not appear to reduce access to gastrostomy for children living in rural/remote locations.

Australian Aboriginal people have significantly poorer health including higher prevalence of illness and significantly shorter life expectancy[45]. At least one third of Aboriginal adults live in areas defined as the lowest $10 \%$ of disadvantage[45] and they experience disparities in access to health services, despite high prevalence of chronic disease[46,47]. Additionally, cultural differences, language barriers and rural or remote residences can preserve disadvantage. We also noticed that the most disadvantaged group ( $1^{\text {st }}$ IRSAD quintile) had greater proportion of Aboriginal children $\left(26.5 \%\right.$ vs $8.8 \%$ in $2^{\text {nd }}-5^{\text {th }}$ IRSAD quintiles) and they were also more likely to live in rural or remote areas. Despite existing disparities, we found a higher rate of first gastrostomy insertion among Aboriginal children compared to their non-Aboriginal peers, driven by increasing numbers of young Aboriginal children undergoing the procedure between 2007 and 2011. While disadvantages often co-occur in different domains, the presence of a centralized public health system in Australia, combining centralized specialist resources, a coordinated rural pediatric service enabling case identification and follow up, and the efforts and influences of clinician champions working in rural and remote areas and targeting Indigenous communities[48] may have impacted this trend allowing for ready access by groups who typically experience poorer access to services. Many Aboriginal children are cared for by different members of the extended family at different times according to cultural practices ("kinship care") and others will have foster carers[49,50], but our findings suggest that that reach to gastrostomy services was retained. 
Our findings provide additional insights into the diagnoses associated with gastrostomy. The 209 "event" likely to have caused the ID was prenatal or perinatal in origin in most children, with the two largest groups being syndromic or following neonatal encephalopathy. Males were more likely to receive a gastrostomy where their ID was associated with chromosomal abnormalities, consistent with the predominance of males with an X-linked ID[51] or in association with preterm birth where males are more commonly affected[52]. The 49 syndromic causes of ID are likely to have been heavily weighted by Rett syndrome, a severe disability affecting approximately 1/10,000 female births where gastrostomy is performed in approximately one quarter of individuals[6]. We were surprised to note that gastrostomy was necessary for some children with Fetal Alcohol Spectrum Disorder, a cause of disability which is usually milder and one that is fully preventable.

$$
\text { Strengths of this study were the longitudinal nature of the population-based data including }
$$
capacity to identify children with ID. However, some children with congenital abnormalities may have had ID but could have died prior to registration and therefore would not have been identified for this study. Moreover, availability of and access to a genetic diagnosis has improved considerably over recent years and information may not have been available from HMDC or IDEA records. Thus our aetiological classification of ID was the best it could be given the information available to us. We also acknowledge that our examination of accessibility to gastrostomy is but one aspect of the delivery of equitable health care. Gastrostomy was accessible across the WA population but our data linkage methodology cannot provide insight on whether the services were culturally and socially acceptable, the extent to which protocols were adaptable to individual child and family needs, and service quality including safety profiling[17].

\section{Conclusion}

We have investigated the use of a procedure designed to improve the delivery of calories and nourishment in children with feeding difficulties and ameliorate the day to day care burden for families. Gastrostomy is used frequently in children with ID and no apparent accessibility barriers 
234 were found in our investigation. More research in relation to long-term outcomes for both child 235 health and carer burden could explain more clearly why more parents are choosing to accept 236 gastrostomy as part of their child's clinical support.

\section{Compliance with Ethical Standards}

Funding: This study was funded by the National Health \& Medical Research Council of Australia (Project grant APP1103746).

Conflict of Interest: The authors declare that they have no conflict of interest.

Ethical approval: All procedures performed in studies involving human participants were in 247 accordance with the ethical standards of the institutional and/or national research committee and 248 with the 1964 Helsinki declaration and its later amendments or comparable ethical standards. 249 Ethical approval was obtained from the Department of Health WA (\#2016/32) and the Western 250 Australian Aboriginal Health Ethics Committee (747)

252 Informed consent: Informed consent was not obtained from individual participants included in the 253 study due to the nature of the anonymized data linkage data. 


\section{REFERENCES}

1. Bourke J, de Klerk N, Smith T, Leonard H (2016) Population-Based Prevalence of Intellectual Disability and Autism Spectrum Disorders in Western Australia: A Comparison with Previous Estimates. Medicine 95(21):e3737.

2. Robertson J, Hatton C, Emerson E, Baines S (2015) Prevalence of Epilepsy among People with Intellectual Disabilities: A Systematic Review. Seizure 29:46-62.

3. Bebbington A, Glasson E, Bourke J, de Klerk N, Leonard H (2013) Hospitalisation Rates for Children with Intellectual Disability or Autism Born in Western Australia 19831999: A Population-Based Cohort Study. BMJ Open 3(2).

4. Bourke J, Nembhard WN, Wong K, Leonard H (2017) Twenty-Five Year Survival of Children with Intellectual Disability in Western Australia. J Pediatr 188:232-239.e232.

5. Sleigh G, Brocklehurst P (2004) Gastrostomy Feeding in Cerebral Palsy: A Systematic Review. Arch Dis Child 89(6):534-539.

6. Downs J, Wong K, Ravikumara M, et al. (2014) Experience of Gastrostomy Using a Quality Care Framework: The Example of Rett Syndrome. Medicine 93(28):e328.

7. $\quad$ Martinez-Costa C, Borraz S, Benlloch C, Lopez-Saiz A, Sanchiz V, Brines J (2011) Early Decision of Gastrostomy Tube Insertion in Children with Severe Developmental Disability: A Current Dilemma. J Hum Nutr Diet 24(2):115-121.

8. Romano C, Dipasquale V, Gottrand F, Sullivan PB (2018) Gastrointestinal and Nutritional Issues in Children with Neurological Disability. Dev Med Child Neurol.

9. Akay B, Capizzani TR, Lee AM, et al. (2010) Gastrostomy Tube Placement in Infants and Children: Is There a Preferred Technique? J Pediatr Surg 45(6):1147-1152.

10. Carpenter JL, Soeken TA, Correa AJ, et al. (2016) Feeding Gastrostomy in Children with Complex Heart Disease: When Is a Fundoplication Indicated? Pediatr Surg Int 32(3):285-289.

11. Daveluy W, Guimber D, Uhlen S, et al. (2006) Dramatic Changes in Home-Based Enteral Nutrition Practices in Children During an 11-Year Period. J Pediatr Gastroenterol Nutr 43(2):240-244.

12. Kvello M, Avitsland TL, Knatten CK, et al. (2016) Trends in the Use of Gastrostomies at a Tertiary Paediatric Referral Centre. Scand J Gastroenterol 51(5):625-632. 13. Quitadamo P, Thapar N, Staiano A, Borrelli O (2016) Gastrointestinal and Nutritional Problems in Neurologically Impaired Children. Eur J Paediatr Neurol 20(6):810-815.

14. Viktorsdottir MB, Oskarsson K, Gunnarsdottir A, Sigurdsson L (2015) Percutaneous Endoscopic Gastrostomy in Children: A Population-Based Study from Iceland, 1999-2010. J Laparoendosc Adv Surg Tech A 25(3):248-251.

15. Glasson EJ, Wong K, Leonard H, et al. (in press) Evolving Trends of Gastrostomy Insertion within a Pediatric Population. J Pediatr Gastroenterol Nutr.

16. United Nations. Convention on the Rights of Persons with Disabilities, Article 25 -

Health. 2018; https://www.un.org/development/desa/disabilities/convention-on-the-rights-ofpersons-with-disabilities/article-25-health.html. Accessed 30 July 2018.

17. Center for Economic and Social Rights. The Opera Framework. Assessing Compliance with the Obligation to Fulfill Economic, Social and Cultural Rights. New York, 2012.

18. Balaratnasingam S, Roy M (2015) Intellectual Disability in Indigenous Australians: Issues and Challenges. Australas Psychiatry 23(6):641-643.

19. Delobel-Ayoub M, Ehlinger V, Klapouszczak D, et al. (2015) Socioeconomic Disparities and Prevalence of Autism Spectrum Disorders and Intellectual Disability. PLoS One 10(11):e0141964. 
20. Leonard H, Petterson B, De Klerk N, et al. (2005) Association of Sociodemographic Characteristics of Children with Intellectual Disability in Western Australia. Soc Sci Med 60(7):1499-1513.

21. Spencer NJ, Blackburn CM, Read JM (2015) Disabling Chronic Conditions in Childhood and Socioeconomic Disadvantage: A Systematic Review and Meta-Analyses of Observational Studies. BMJ Open 5(9):e007062.

22. Totsika V, Hastings RP, Vagenas D (2017) Informal Caregivers of People with an Intellectual Disability in England: Health, Quality of Life and Impact of Caring. Health Soc Care Community 25(3):951-961.

23. Zheng X, Chen R, Li N, et al. (2012) Socioeconomic Status and Children with Intellectual Disability in China. J Intellect Disabil Res 56(2):212-220.

24. ABS. Australian Demographic Statistics, Cat. No. 3101.0. Canberra, Australia: Australian Bureau of Statistics;2017.

25. ABS. Regional Population Growth, Australia, Cat. No. 3218.0. Canberra, Australia: Australian Bureau of Statistics;2016.

26. Holman CDJ, Bass AJ, Rosman DL, et al. (2008) A Decade of Data Linkage in Western Australia: Strategic Design, Applications and Benefits of the WA Data Linkage System. Aust Health Review 32(4):766-777.

27. Holman CDJ, Bass AJ, Rouse IR, Hobbs MST (1999) Population-Based Linkage of Health Records in Western Australia: Development of a Health Services Research Linked Database. A N Z J Public Health 23:453-459.

28. Leonard H, Glasson E, Bebbington A, et al. Application of Population-Based Linked Data to the Study of Intellectual Disability and Autism. In: Urbano RC, ed. International Review of Research in Developmental Disabilities. Vol 45. Burlington: Academic Press; 2013:281-327.

29. Petterson B, Leonard H, Bourke J, et al. (2005) Idea (Intellectual Disability Exploring Answers): A Population-Based Database for Intellectual Disability in Western Australia. Ann Hum Biol 32(2):237-243.

30. Australian Bureau of Statistics. Australian Bureau of Statistics. http://www.abs.gov.au/, 2018.

31. Christensen D, Davis G, Draper G, et al. (2014) Evidence for the Use of an Algorithm in Resolving Inconsistent and Missing Indigenous Status in Administrative Data Collections. Aust Journal Soc Issues 49(4):423-443.

32. Yeargin-Allsopp M, Murphy CC, Cordero JF, Decoufle P, Hollowell JG (1997) Reported Biomedical Causes and Associated Medical Conditions for Mental Retardation among 10-Year-Old Children, Metropolitan Atlanta, 1985 to 1987. Dev Med Child Neurol 39(3):142-149.

33. Avitsland TL, Kristensen C, Emblem R, Veenstra M, Mala T, Bjornland K (2006) Percutaneous Endoscopic Gastrostomy in Children: A Safe Technique with Major Symptom Relief and High Parental Satisfaction. J Pediatr Gastroenterol Nutr 43(5):624-628.

34. Jensen AR, Renaud E, Drucker NA, et al. (2017) Why Wait: Early Enteral Feeding after Pediatric Gastrostomy Tube Placement. J Pediatr Surg.

35. Sevilla WM, McElhanon B (2016) Optimizing Transition to Home Enteral Nutrition for Pediatric Patients. Nutr Clin Pract 31(6):762-768.

36. Fox D, Campagna EJ, Friedlander J, Partrick DA, Rees DI, Kempe A (2014) National Trends and Outcomes of Pediatric Gastrostomy Tube Placement. J Pediatr Gastroenterol Nutr 59(5):582-588.

37. Dybwad G. Action Implications, USA Today. In: Kugel RB, Wolfensberger W, eds. Changing Patterns in Residential Services for the Mentally Retarded. Washington DC: President's Committee on Mental Retardation; 1969:383-428. 
38. Mencap. The Nhs - Health for All? People with Learning Disabilities and Health Care. London: Mencap; 1998.

39. Nirje B. The Normalization Principle and Its Human Management Implications. In: Kugel RB, Wolfensberger W, eds. Changing Patterns in Residential Services for the Mentally Retarded. Washington DC: President's Committee on Mental Retardation; 1969:179-195. 40. US Public Health Service. Closing the Gap: A National Blueprint for Improving the Health of Individuals with Mental Retardation. Report of the Surgeon General's Conference on Health Disparities and Mental Retardation. Washington, D.C. Feburary, 20012001.

41. Bourke J, de Klerk N, Smith T, Leonard H (2016) Population-Based Prevalence of Intellectual Disability and Autism Spectrum Disorders in Western Australia: A Comparison with Previous Estimates. Medicine 95(21):e3737.

42. Boyce K, White C, Hunt P, et al. (2018) Inequalities in Health? An Update on the Effect of Social Deprivation for Patients with Breast Cancer in South East Wales. Surgeon. 43. Wasif N, Etzioni D, Habermann EB, et al. (2018) Racial and Socioeconomic Differences in the Use of High-Volume Commission on Cancer-Accredited Hospitals for Cancer Surgery in the United States. Ann Surg Oncol 25(5):1116-1125.

44. Gallego G, Dew A, Lincoln M, et al. (2017) Access to Therapy Services for People with Disability in Rural Australia: A Carers' Perspective. Health Soc Care Community 25(3):1000-1010.

45. Australian Health Ministers' Advisory Council. Aboriginal and Torres Strait Islander Health Performance Framework 2014 Report. Canberra, Australia: AHMAC;2015.

46. Al-Yaman F (2017) The Australian Burden of Disease Study: Impact and Causes of Illness and Death in Aboriginal and Torres Strait Islander People, 2011. Public Health Res Pract 27(4).

47. Randall DA, Reinten T, Maher L, et al. (2014) Disparities in Cataract Surgery between Aboriginal and Non-Aboriginal People in New South Wales, Australia. Clin Exp Ophthalmol 42(7):629-636.

48. Brewster DR, Morris PS (2015) Indigenous Child Health: Are We Making Progress? J Paediatr Child Health 51(1):40-47.

49. Maclean MJ, Taylor CL, O'Donnell M (2017) Relationship between out-of-Home Care Placement History Characteristics and Educational Achievement: A Population Level Linked Data Study. Child Abuse Negl 70:146-159.

50. Zubrick SR, Lawrence DM, Silburn SR, et al. The Western Australian Aboriginal Child Health Survey: The Health of Aboriginal Children and Young People. Perth: Telethon Institute for Child Health Research;2004.

51. Gecz J, Shoubridge C, Corbett M (2009) The Genetic Landscape of Intellectual Disability Arising from Chromosome X. Trends Genet. 25(7):308-316.

52. Di Renzo GC, Rosati A, Sarti RD, Cruciani L, Cutuli AM (2007) Does Fetal Sex Affect Pregnancy Outcome? Gend Med 4(1):19-30. 
Table 1. Characteristics of 11,729 children with intellectual disability born in WA (19832009), by gastrostomy status.

\begin{tabular}{|c|c|c|}
\hline & No gastrostomy & Gastrostomy \\
\hline $\mathrm{N}$ & 11,404 & 325 \\
\hline Year of birth & $\mathrm{n}($ row $\%)(\operatorname{col} \%)$ & $\mathrm{n}(\mathrm{row} \%)(\operatorname{col} \%)$ \\
\hline 1983-1984 & $551(97.5)(4.8)$ & $14(2.5)(4.3)$ \\
\hline 1985-1989 & $2,075(98.2)(18.2)$ & $38(1.8)(11.7)$ \\
\hline 1990-1994 & $2,716(97.2)(23.8)$ & $78(2.8)(24.0)$ \\
\hline $1995-1999$ & $2,297(97.3)(20.1)$ & $64(2.7)(19.7)$ \\
\hline $2000-2004$ & $1,991(96.6)(17.5)$ & $70(3.4)(21.5)$ \\
\hline $2005-2009$ & $1,774(96.7)(15.6)$ & $61(3.3)(18.8)$ \\
\hline \multicolumn{3}{|l|}{ Sex } \\
\hline Male & $7,488(97.7)(65.7)$ & $174(2.3)(53.5)$ \\
\hline Female & $3,916(96.3)(34.3)$ & $151(3.7)(46.5)$ \\
\hline \multicolumn{3}{|l|}{ Severity level of intellectual disability } \\
\hline Mild/Moderate & $10,526(98.9)(92.3)$ & $118(1.1)(36.3)$ \\
\hline Severe & $686(77.9)(6.0)$ & $195(22.1)(60.0)$ \\
\hline Missing & $192(94.1)(1.7)$ & $12(5.9)(3.7)$ \\
\hline \multicolumn{3}{|l|}{ Indigenous status } \\
\hline Non-indigenous & $9,787(97.2)(85.8)$ & $280(2.8)(86.1)$ \\
\hline Indigenous & $1,617(97.3)(14.2)$ & $45(2.7)(13.9)$ \\
\hline \multicolumn{3}{|l|}{ Remoteness area } \\
\hline Major cities & $7,289(97.3)(63.2)$ & $200(2.7)(61.5)$ \\
\hline Regional or remote & $2,994(96.8)(26.3)$ & $98(3.2)(30.2)$ \\
\hline Missing & $1,201(97.8)(10.5)$ & $27(2.2)(8.3)$ \\
\hline \multicolumn{3}{|l|}{ IRSAD quintile } \\
\hline $1 \mathrm{st}(<=20 \%)$ & $3,331(97.6)(29.2)$ & $83(2.4)(25.5)$ \\
\hline 2nd $(21-40 \%)$ & $2,524(97.1)(22.1)$ & $75(2.9)(23.1)$ \\
\hline 3rd $(41-60 \%)$ & $1,893(97.2)(16.6)$ & $55(2.8)(16.9)$ \\
\hline 4th $(61-80 \%)$ & $1,425(96.0)(12.5)$ & $59(4.0)(18.2)$ \\
\hline 5 th $(>80 \%)$ & $1,035(97.5)(9.1)$ & $26(2.5)(8.0)$ \\
\hline Missing & $1,196(97.8)(10.5)$ & $27(2.2)(8.3)$ \\
\hline Age at admission (years), median (IQR) & & $3.4(1.6,7.9)$ \\
\hline \multicolumn{3}{|l|}{ Age at admission (years) } \\
\hline $0-2$ & & $149(45.8)$ \\
\hline $3-5$ & & $78(24.0)$ \\
\hline $6-8$ & & $32(9.8)$ \\
\hline $9-11$ & & $24(7.4)$ \\
\hline $12-14$ & & $20(6.2)$ \\
\hline $15-17$ & & $22(6.8)$ \\
\hline \multicolumn{3}{|l|}{ Year of procedure } \\
\hline 1983-1999 & & $122(37.5)$ \\
\hline $2000-2009$ & & $143(44.0)$ \\
\hline $2010-2014$ & & $60(18.5)$ \\
\hline
\end{tabular}


Table 2. Subgroup analysis of annual percentage change of age-specific incidence rates of first gastrostomy insertion over calendar year, by socioeconomic status, remoteness area and Aboriginality.

\begin{tabular}{|c|c|c|c|c|c|c|}
\hline & \multicolumn{2}{|c|}{$\begin{array}{l}\text { Socioeconomic status } \\
\left(1^{\text {st }} \text { IRSAD quintile vs } 2^{\text {nd }}-\right. \\
5^{\text {th }} \text { IRSAD quintile } \\
\text { [baseline] })\end{array}$} & \multicolumn{2}{|c|}{$\begin{array}{l}\text { Remoteness area } \\
\text { (regional/remote vs. } \\
\text { major cities [baseline]) }\end{array}$} & \multicolumn{2}{|c|}{$\begin{array}{l}\text { Aboriginality } \\
\text { (Aboriginal vs. non- } \\
\text { Aboriginal [baseline]) }\end{array}$} \\
\hline & Unadjusted & Adjusted $^{\mathrm{a}}$ & Unadjusted & Adjusted $^{\mathrm{b}}$ & Unadjusted & Adjusted $^{\mathrm{c}}$ \\
\hline Age group & $\beta(95 \% \mathrm{CI})$ & $\beta(95 \% \mathrm{CI})$ & $\beta(95 \% \mathrm{CI})$ & $\beta(95 \% \mathrm{CI})$ & $\beta(95 \% \mathrm{CI})$ & $\beta(95 \% \mathrm{CI})$ \\
\hline $0-2$ years & $\begin{array}{l}3.9 \\
(-1.8,10.0)\end{array}$ & $\begin{array}{l}1.8 \\
(-3.8,7.7)\end{array}$ & $\begin{array}{l}5.1 \\
(0.4,10.9)\end{array}$ & $\begin{array}{l}3.4 \\
(-2.1,9.2)\end{array}$ & $\begin{array}{l}15.5 \\
(7.4,24.1)\end{array}$ & $\begin{array}{l}12.6 \\
(4.4,21.4)\end{array}$ \\
\hline $3-5$ years & $\begin{array}{l}4.8 \\
(-3.3,13.6)\end{array}$ & $\begin{array}{l}2.6 \\
(-4.7,10.5)\end{array}$ & $\begin{array}{l}5.2 \\
(-2.4,13.4)\end{array}$ & $\begin{array}{l}3.0 \\
(-4.3,10.9)\end{array}$ & $\begin{array}{l}15.1 \\
(1.9,29.9)\end{array}$ & $\begin{array}{l}13.6 \\
(0.8,28.0)\end{array}$ \\
\hline
\end{tabular}

IRSAD, The Index of Relative Socio-Economic Advantage and Disadvantage; $\beta$, APC difference (\%); CI, confidence interval

\footnotetext{
${ }^{a}$ adjusted for Aboriginality and remoteness, and their interaction terms with calendar time

$\mathrm{b}$ adjusted for socio-economic status and Aboriginality, and their interaction terms with calendar time

${ }^{\mathrm{c}}$ adjusted for socio-economic status and remoteness, and their interaction terms with calendar time
} 
Table 3: Etiologies of intellectual disability in children who underwent gastrostomy insertion $(n=325)$.

\begin{tabular}{|c|c|c|c|c|c|c|c|}
\hline & & & \multirow[t]{2}{*}{$\mathrm{N}(\%)$} & \multicolumn{2}{|c|}{$\begin{array}{c}\text { Age first gastrostomy } \\
\text { (years) }\end{array}$} & \multicolumn{2}{|c|}{ Sex, n (row \%) } \\
\hline & & & & Median & IQR & Male & Female \\
\hline \multirow{10}{*}{$\begin{array}{l}\text { Prenatal } \\
(\mathrm{n}=184, \\
56.6 \%)\end{array}$} & \multirow[t]{4}{*}{$\begin{array}{l}\text { Genetic } \\
(\mathrm{n}=110,33.8 \%)\end{array}$} & $\begin{array}{l}\text { Genetic } \\
\text { syndromes/mitochondrial }\end{array}$ & $49(15.1)$ & 2.5 & $1.1-8.2$ & $17(34.7)$ & $32(65.3)$ \\
\hline & & Metabolic disorders & $25(7.7)$ & 3.1 & $1.6-4.2$ & $15(60.0)$ & $10(40.0)$ \\
\hline & & Chromosomal & $19(5.8)$ & 1.7 & $1.0-3.3$ & $14(73.7)$ & $5(26.3)$ \\
\hline & & Neuronal migration disorder & $17(5.2)$ & 3.5 & $1.3-6.0$ & $9(52.9)$ & $8(47.1)$ \\
\hline & \multirow{4}{*}{$\begin{array}{l}\text { Birth defects } \\
(n=43,13.2 \%)\end{array}$} & Structured cerebral defect & $15(4.6)$ & 3.2 & $1.6-6.0$ & $6(40.0)$ & $9(60.0)$ \\
\hline & & Microcephaly & $11(3.4)$ & 9.0 & $2.5-12.6$ & $6(54.6)$ & $5(45.4)$ \\
\hline & & Hydrocephalus & $9(2.8)$ & 9.0 & $2.6-9.7$ & $*$ & $*$ \\
\hline & & $\begin{array}{l}\text { Multiple congenital } \\
\text { abnormalities }\end{array}$ & $8(2.5)$ & 1.8 & $1.0-4.4$ & $*$ & $*$ \\
\hline & \multirow{2}{*}{$\begin{array}{l}\text { Teratogenic } \\
(\mathrm{n}=31,9.5 \%)\end{array}$} & Congenital infection & $21(6.5)$ & 4.5 & $2.0-8.7$ & $7(33.3)$ & $14(66.7)$ \\
\hline & & $\begin{array}{l}\text { Fetal Alcohol Spectrum } \\
\text { Disorder }\end{array}$ & $10(3.1)$ & 1.8 & $0.5-2.7$ & $*$ & $*$ \\
\hline \multirow{4}{*}{$\begin{array}{l}\text { Perinatal } \\
(\mathrm{n}=91, \\
28.0 \%)\end{array}$} & \multirow{2}{*}{$\begin{array}{l}\text { Intrauterine/intrapartum } \\
(\mathrm{n}=67,20.6 \%)\end{array}$} & Neonatal encephalopathy & $48(14.8)$ & 4.4 & $1.8-8.6$ & $32(66.7)$ & $16(33.3)$ \\
\hline & & Prematurity & $19(5.8)$ & 2.0 & $0.6-8.7$ & $*$ & $*$ \\
\hline & \multirow{2}{*}{$\begin{array}{l}\text { Neonatal } \\
(\mathrm{n}=24,7.4 \%)\end{array}$} & Epileptic encephalopathy & $18(5.5)$ & 2.9 & $2.5-6.4$ & $12(66.7)$ & $6(33.3)$ \\
\hline & & Neonatal/Other unspecified & $6(1.8)$ & 3.2 & $2.8-5.6$ & $*$ & $*$ \\
\hline \multirow{2}{*}{\multicolumn{2}{|c|}{ Post neonatal $(\mathrm{n}=23,7.1 \%)$}} & Injury or asphyxia & $15(4.6)$ & 8.1 & $3.7-14.2$ & $6(40.0)$ & $9(60.0)$ \\
\hline & & Meningitis/Encephalitis & $8(2.5)$ & 4.8 & $2.3-12.4$ & $*$ & $*$ \\
\hline \multicolumn{3}{|c|}{ Miscellaneous $(\mathrm{n}=27,8.3 \%)$} & $27(8.3)$ & 5.8 & $3.6-8.5$ & $16(59.3)$ & $11(40.7)$ \\
\hline
\end{tabular}

* Data not presented for cell counts if either gender contained less than five cases. 
Figure 1. Age specific incidence rates of first gastrostomy insertion over calendar year (1983-2014) in children born alive in Western Australia between 1983 and 2009.

Figure 2. Age specific incidence rates of first gastrostomy insertion over calendar year (1983-2014) in children born alive in Western Australia between 1983 and 2009, presenting children whose families were in the most disadvantaged group ( $1^{\text {st }}$ IRSAD quintile) compared with families in more advantaged groups $\left(2^{\text {nd }}-5^{\text {th }}\right.$ IRSAD quintiles $)$.

Figure 3. Age specific incidence rates of first gastrostomy insertion over calendar year (1983-2014) in children born alive in Western Australia between 1983 and 2009, presenting children whose families lived in regional/remote communities compared with those who lived in major cities.

Figure 4. Age specific incidence rates of first gastrostomy insertion over calendar year (1983-2014) in children born alive in Western Australia between 1983 and 2009, presenting children who were Aboriginal compared with those who were non-Aboriginal. 
Fig 1 Age specific incidence rates of first gastrostomy insertion over calendar year (19832014) in children born alive in Western Australia between 1983 and 2009

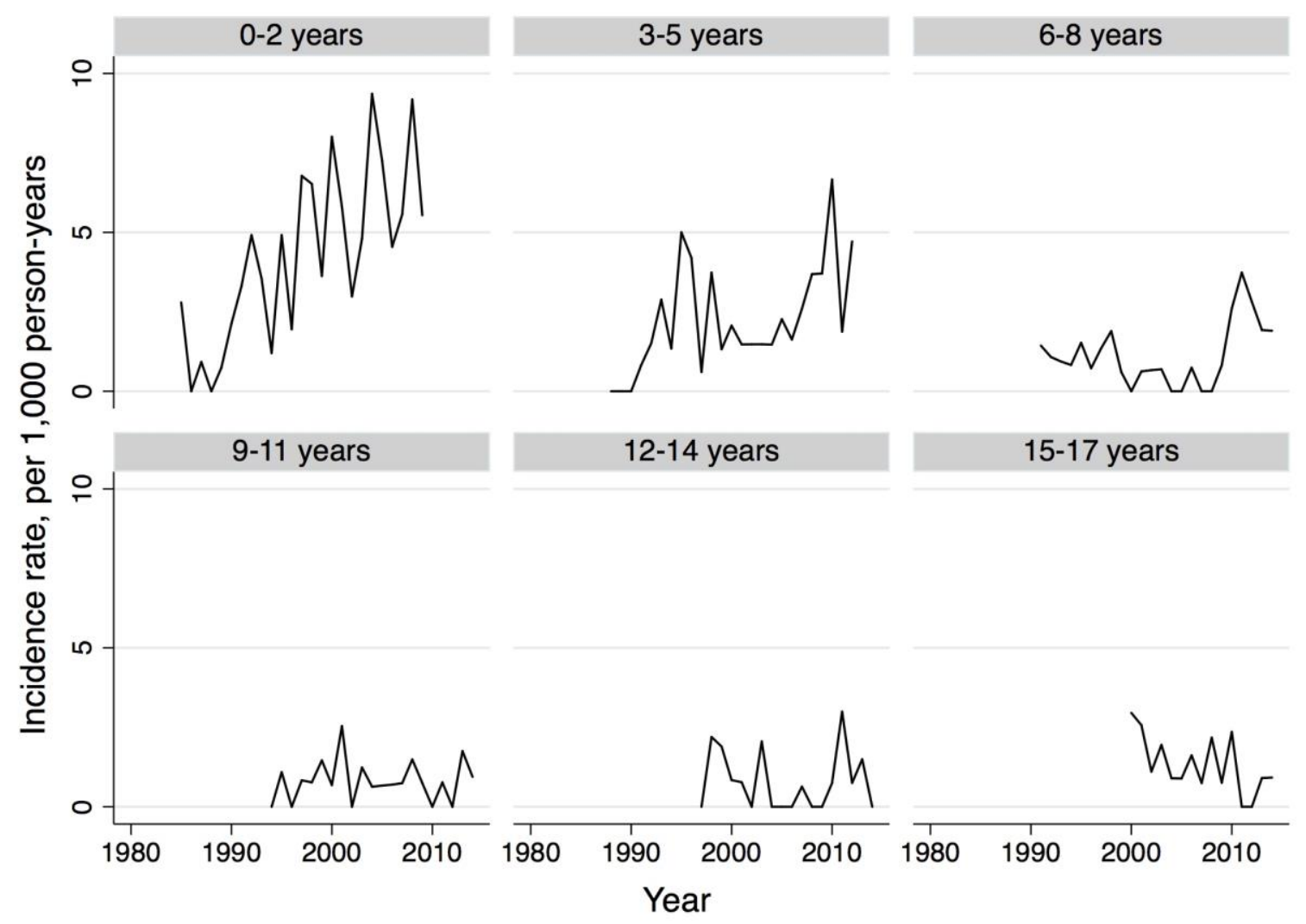


Fig 2 Age specific incidence rates of first gastrostomy insertion over calendar year (19832014) in children born alive in Western Australia between 1983 and 2009, presenting children whose families were in the most disadvantaged group ( $1^{\text {st }}$ IRSAD quintile) compared with families in more advantaged groups $\left(2^{\text {nd }}-5^{\text {th }}\right.$ IRSAD quintiles $)$

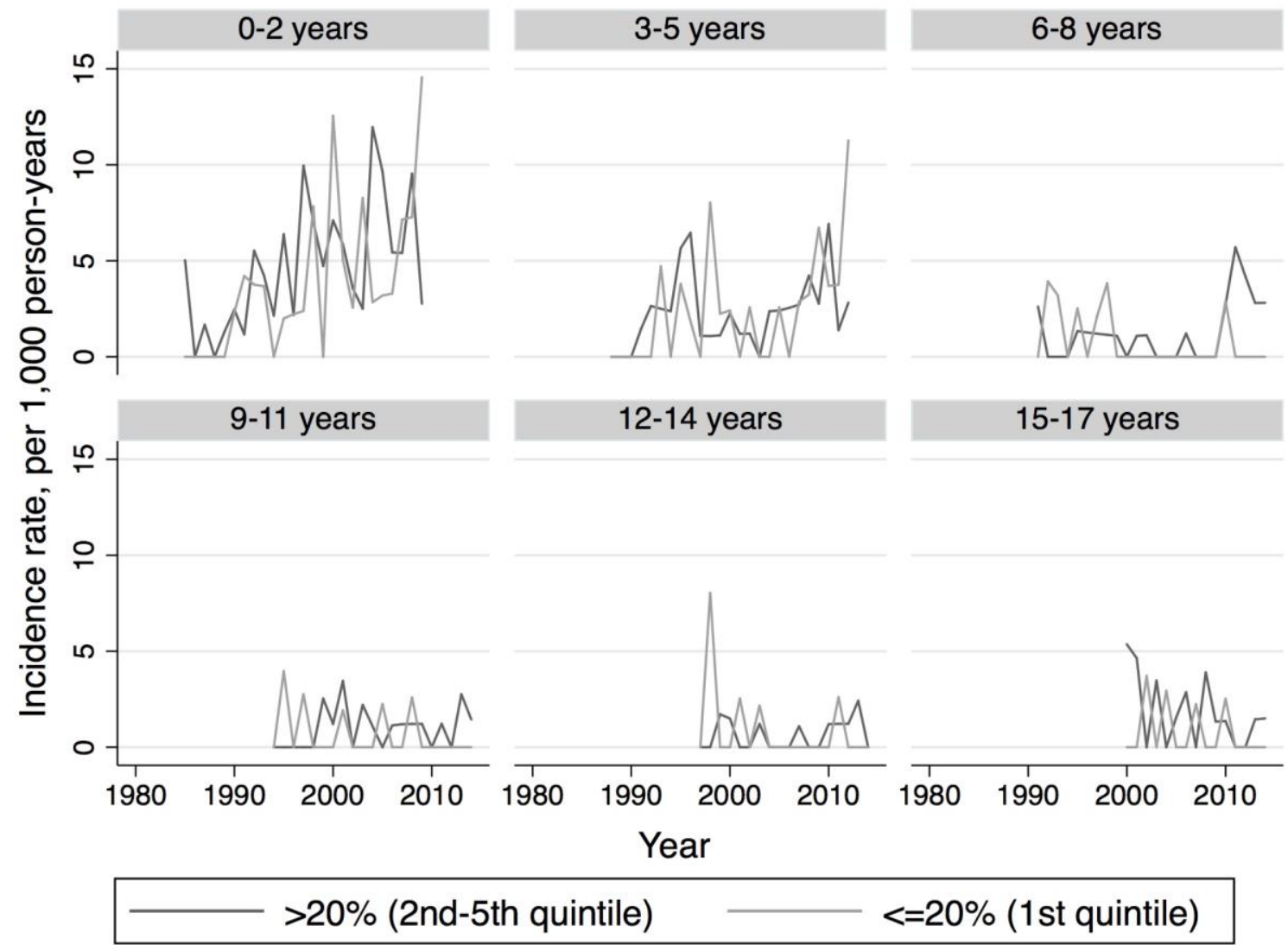


Fig 3 Age specific incidence rates of first gastrostomy insertion over calendar year (19832014) in children born alive in Western Australia between 1983 and 2009, presenting children whose families lived in regional/remote communities compared with those who lived in major cities

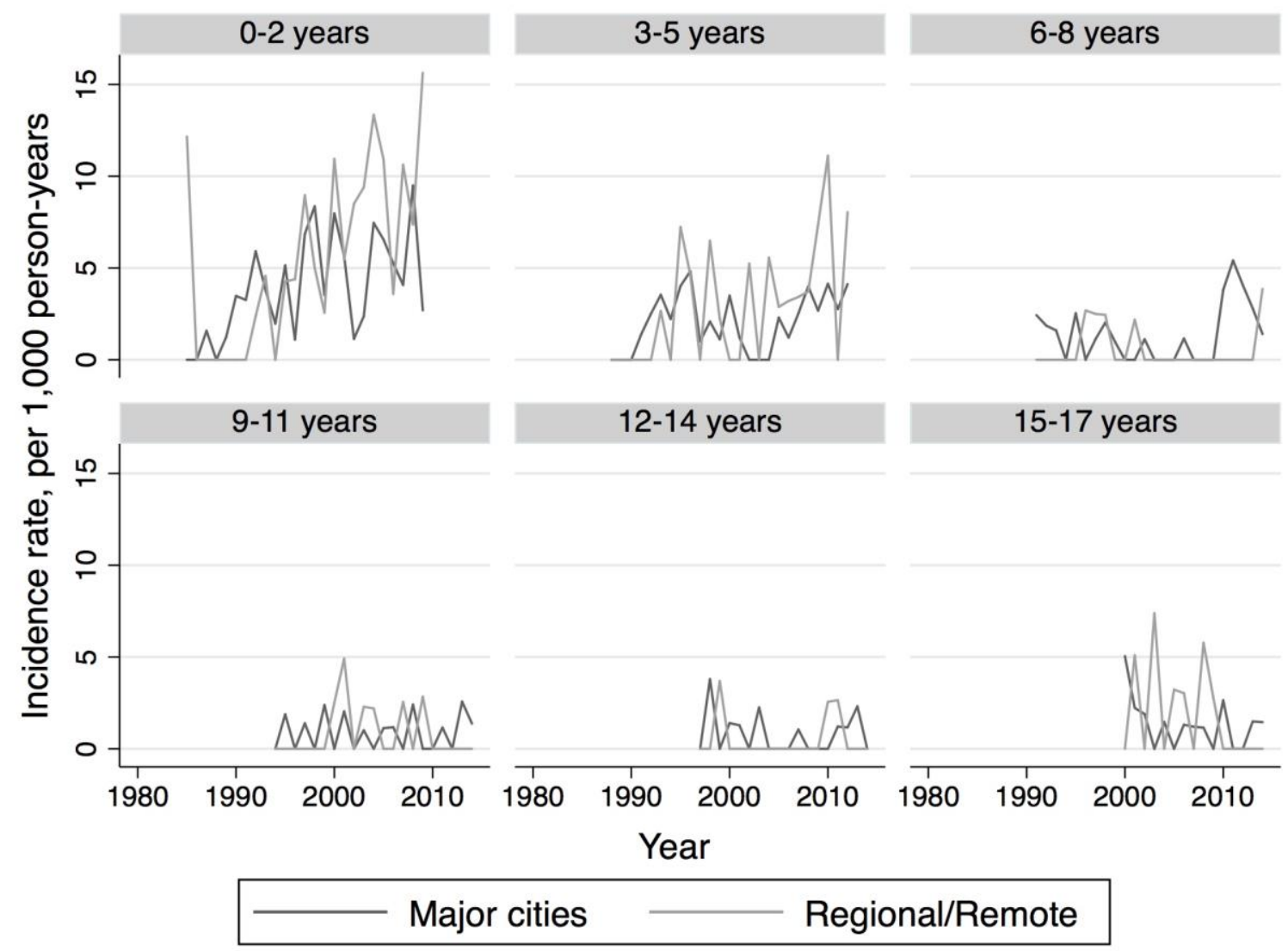


Fig 4 Age specific incidence rates of first gastrostomy insertion over calendar year (19832014) in children born alive in Western Australia between 1983 and 2009, presenting children who were Aboriginal compared with those who were non-Aboriginal

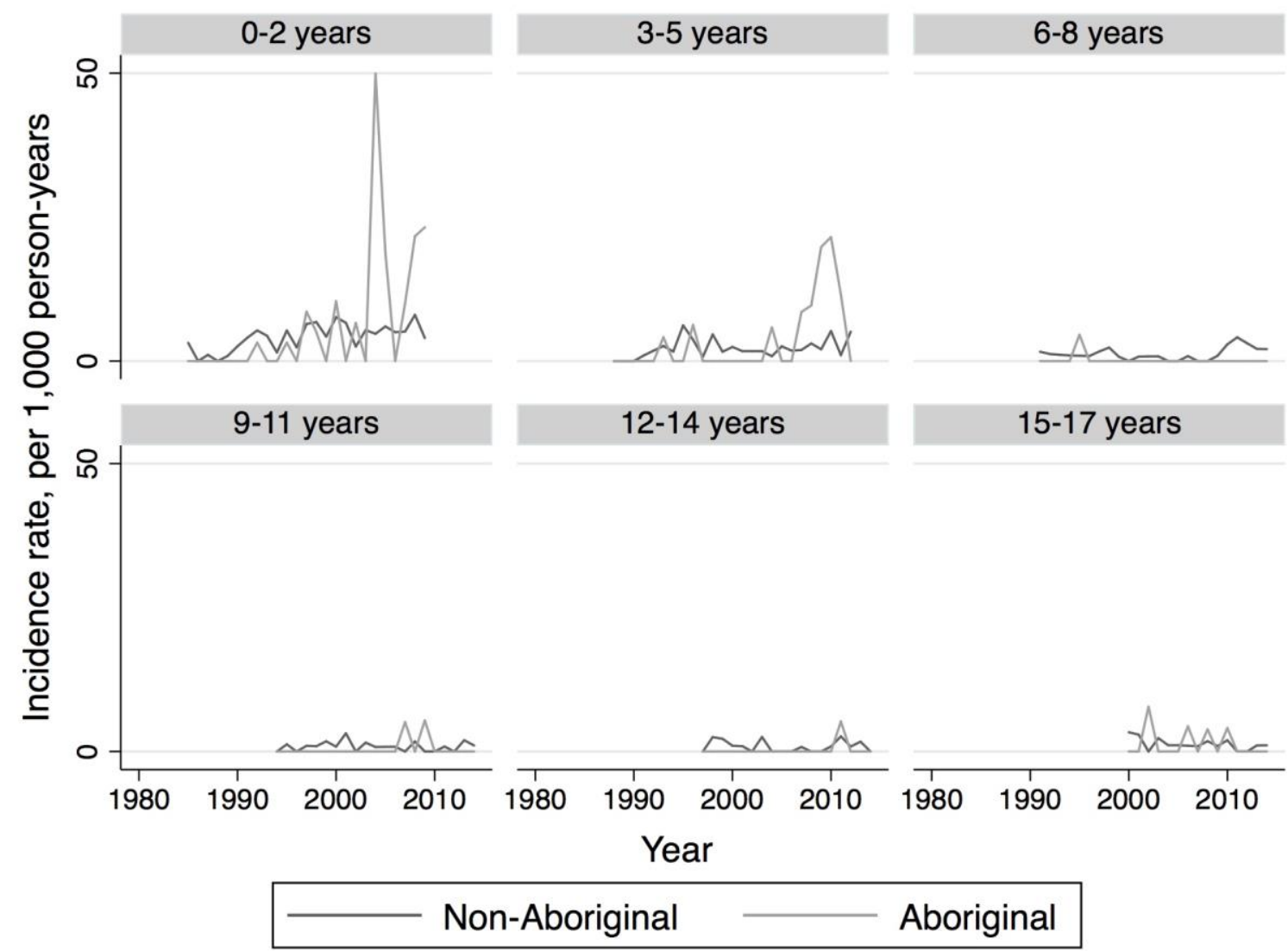

